\title{
Notas y documentos
}

\section{"REALIDAD DE HOY, ES FRUTO DE VISION DE FUNDADORES Y ESFUERZO DE REALIZADORES”}

El rector de la Universidad de Concepción, señor David Stitchkin Branover, dijo, con motivo de celebrarse el Día de la Universidad, el siguiente mensaje radial:

"La Universidad celebra hoy sus treinta y ocho años de existencia. Al recordar este aniversario de su fundación, sobrecoge pensar en el desarrollo alcanzado en tan breve tiempo. La bella y esplendorosa realidad de hoy es el fruto maduro de la visión de sus fundadores y del esfuerzo de sus realizadores. Es hermoso reflexionar sobre la enorme cantidad de energías, esfuerzo, amor y sacrificios de todos los hombres que han labrado los cimientos de este Instituto. Conviviendo a cada instante con los profesores, decanos, directores y personal administrativo de la Universidad, se siente una profunda estimación, admiración y respeto por todos y cada uno de ellos. Pues la Universidad no es el resultado de un cuerpo de edificios, ni de aparatos de laboratorio, sino de la voluntad puesta por cada uno de sus miembros en una tarea común, constante, que ha de realizarse a diario venciendo toda clase de dificultades e imponiéndose un duro y mantenido sacrificio.

"La abnegada actitud y colaboración del cuerpo docente; la renovada inquietud del honorable consejo; la generosa, desinteresada, activa y fecunda actitud de los miembros del honorable directorio; 
la leal cooperación del personal administrativo; todo ello es la continuación de la voluntad de realización de los fundadores de la Universidad. Y así resulta que las voluntades mancomunadas de los hombres de ayer y de los hoy, son el firme cimiento en que se levanta esta Universidad.

"La celebración de hoy coincide con el término del primer añ̀o de ejercicio de la rectoría que el Claustro Pleno puso en mis manos. Nuestro más firme y decidido pensamiento ha sido y será mantener en la Universidad el sello que le impuso la voluntad de sus fundadores. Este alto Instituto, nacido bajo el signo de la universalidad del saber, continuará siendo fundamentalmente un centro de estudios científicos y humanísticos de alto rango, paralelamente al ejercicio de las tareas docentes y de extensión cultural.

"La Universidad de Concepción no perderá, pues, su sello distintivo y no se descuidará su misión específica. Ello no obsta al mantenimiento y acentuación de nuestro claro y decidido propósito de colocar a la Universidad en una estrecha colaboración con todas las actividades productoras de la región y del país. Todo el servicio que la Universidad puede prestar en el estímulo, desarrollo y progreso de las actividades industriales, agropecuarias y comerciales, se dará generosamente como un deber de este Instituto para con el país y la región en la que está enclavada. Del mismo modo, se dará servicio cultural amplio y permanente a nuestro pueblo, que debe gozar de las ventajas de la cultura sin mezquindad, cualquiera que sea el sacrificio económico y el esfuerzo personal que esa acción requiera.

"La Universidad ha estrechado sus vinculaciones con las demás Universidades del país, pues entendemos que es indispensable mancomunar la acción de todas ellas en bien de nuestra tierra y del progreso de la ciudadanía toda. Así ha sido nuestro huésped hace pocos días, el rector de la Universidad de Chile y lo será dentro de escaso tiempo, el rector de la Universidad Católica de Valparaíso, padre González Foester.

"En el terreno material, levantaremos en poco tiempo más la Biblioteca Central, que sirve tanto a la Universidad como a todos los 
centros educacionales de esta región; levantaremos el Instituto de Ciencias Naturales, con sus Departamentos de Botánica, Zoología Agrícola, Hidrobiología y Entomología; se construirá el edificio complementario del Instituto Tecnológico para dar satisfacción a las ne= cesidades de la carrera de Ingeniería Mecánica y a las Licenciaturas en Física, Química y Matemáticas. Y se estudia el programa de necesidades para el nuevo edificio de la Escuela Dental.

"La Federación de Estudiantes ha recibido y mantenido impulso en favor de todos los programas que ha presentado dentro de la órbita de su acción propia. Y esperamos que será una realidad, merced al concurso del honorable directorio, la construcción de la Casa de la Federación.

"Ninguna acción sería posible sin el estímulo que hemos recibido de todos los sectores de la ciudadanía penquista y de todas las regiones sureñas que reclaman una acción directa de la Universidad, a las que se dará y se está dando especial atención. Este estímulo se advierte particularmente en la prensa y en la radio, órganos de publicidad que nos alientan y que impulsan generosamente las iniciativas de esta Casa de Estudios. Expreso mis agradecimientos y los de los cuerpos directivos de la Universidad, a la prensa y a las radioemisoras de Concepción y Talcahuano. '

"Hemos recibido un cable del señor Rector Vitalicio de la Universidad, don Enrique Molina, en que lamenta su ausencia accidental y se asocia a la celebración de hoy. Pero don Enrique no está ausente. Su nombre y su espíritu están en la mente y en los corazones de todos los universitarios y es y será guía y bandera de nuestra acción presente y futura.

"Creo firmemente que podemos mirar con confianza el porvenir. La Universidad de Concepción es una parte viva de esta ciudad, de esta provincia, de nuestra tierra. La voluntad común de todos es elevarla cada día más alto hacia la realización cabal de su legítimo destino. Con la ayuda de todos, el camino será más fácil. $\mathrm{Y}$ en lo que a nosotros toca, no escatimaremos esfuerzo alguno para enaltecer la obra de los fundadores y llevarla a su plena realización. Pues no 
debe olvidarse jamás que la Universidad es una cosa viva, que sólo se realiza en cuanto sigue creciendo y avanzando en el campo de la ciencia, de la moral y del espíritu".

\section{LA CELEBRACION DEL DIA DE LA UNIVERSIDAD}

En un brillante acto, con ribetes de intensa emotividad, se celebró en el Teatro Concepción el Día de la Universidad, con la asistencia de las autoridades civiles, militares y eclesiásticas de la provincia; decano del Cuerpo Consular; jefes educacionales de Concepción, estudiantes y un numeroso público que llenó las diversas aposentadurías del anfiteatro.

\section{ACTUACION DE LOS COROS}

Bajo la dirección de Heles Contreras, los Coros de la Universidad, que contaron también con la actuación del organista Hermann Kock, dieron comienzo al acto de celebración, interpretando con gran acierto el himno del Coro Universitario y luego "To Shorten Winter's Sadness", de Thomas Weekel; Aleluya de "El Mesías", de Haendel, y los Coros N." 5, 11 y 14, de "La Creación", de Haydn, con la actuación sobresaliente del trío formado por la soprano Olga Muñoz, el tenor Leonel Cartes y el barítono Reynaldo Sepúlveda.

\section{ENTREGA DE LOS PREMIOS}

Luego, a nombre de la Universidad de Concepción, hizo uso de la palabra el director de la Escuela de Ingeniería Química, señor Salvador Gálvez Rojas, quien terminó su discurso embargado por una intensa y genuina emoción, pues el señor Gálvez es también uno de los fundadores del plantel. Fue largamente aplaudido por los asistentes.

A continuación el rector, señor David Stitchkin, dijo unas breves palabras, antes de hacer entrega del diploma que acredita como Miem- 
bro Honorario de la Universidad de Concepción, al profesor fundador, señor Humberto Vergara Droguett.

Cabe destacar, que después de la actuación de los coros ocuparon el proscenio las autoridades universitarias y autoridades civiles, militares y eclesiásticas de la provincia, especialmente invitadas.

Seguidamente se procedió a hacer entrega de los premios "Universidad de Concepción”, cuya nómina damos en información aparte y los premios donados por las instituciones y corporaciones que indicamos:

Premio Banco de Concepción, a los señores Avelino García Uteau, Jorge Navarrete González y Alfredo Hoffman Schlack.

Premio "Julio Parada Benavente", al señor Iván Calderón y señorita Eugenia Aravena Freude.

Premio "Instituto de Ingenieros y Arquitectos", señores Sergio Miranda Casanova y James Steel Gubbins.

Premio "Colegio Farmacéutico de Chile", al señor Edmundo Garcés Garcés.

Premio "Alcibíades Santa Cruz", al señor Clodomiro Almeyda Pairoa.

Premio "Tomás Olivieri”, al señor Juan Muñoz Burboa.

Premio "Carlos Jarpa de la Cruz", donado por el personal docente de la Clínica de Odontopediatría, consistente en una obra científica de la especialidad, al señor Hein Werneister Schilling, del V año de Odontología.

A continuación se hizo entrega de los diplomas de estímulo a los señores Gastón von dem Busche Aranda, por su labor en el Teatro Universitario; Bernardino Sanhueza Pino, por su labor en Extensión Cultural, como representante de la FEC.; Heles Contreras Weibel, como creador del conjunto coral; Daniel Escalona de la Torre, como organizador de la Primera Exposición Internacional de Motivos Periodísticos, de Publicidad y de Fotografía; Bernardo Binieck Papernik, por su actuación en las actividades deportivas. 


\section{DISCURSO A NOMBRE DE LOS EGRESADOS}

Finalmente hizo uso de la palabra a nombre de los egresados premiados, la señorita Irma Bavestrello Bontá, de la Escuela de Leyes, quien en su discurso expresó, entre otras cosas:

"El desarrollo intelectual de nuestros tiempos ha dejado atrás los infundados convencionalismos, que imperantes hasta mediados del siglo XIX, impedían el trabajo de la mujer. Hoy por hoy, se comprende la fuerza económica que ella representa con su esfuerzo físico e intelectual.

"El trabajo más apropiado para la mujer es el que despliega en una profesión cualquiera; no valoramos más una que otra; todas ellas, desde la más humilde a la más elevada, honran, enaltecen y tienen igual importancia ante los hechos económicos y ante la prosperidad nacional, siempre que se ejerzan con tesón, entusiasmo y fe".

A continuación siguió destacando los beneficios que se obtienen con la educación de la mujer y terminó agradeciendo a los maestros, no sólo por la ciencia inculcada, sino también por la ética profesional que enseñaron. Agradeció, también, a las autoridades universitarias, ofreciéndoles todos los éxitos que tenga en su labor futura, como igualmente los de sus compañeros.

\section{DISCURSO DE D. SALVADOR GALVEZ}

Señor Intendente, autoridades civiles, judiciales, militares, navales y eclesiásticas; señor rector, señores consejeros y directores de la Universidad, señoras y señores, jóvenes alumnos:

"En este acto solemne con que se celebra el día de la Universidad y en que se entregan los premios a los mejores alumnos que han terminado sus estudios en 1956 , se me ha pedido pronunciar un discurso. Grande honor para un viejo servidor de la institución; pero no pudiendo hacer un discurso académico me voy a permitir contar, 
breve y sumariamente, cómo nació esta obra, hoy día grandiosa, para que las jóvenes generaciones puedan apreciar lo que se ha hecho, con los modestos recursos de que se ha dispuesto, en un plazo tan breve para la vida de una Universidad y les sirva de aliciente, más adelante.

Desde los albores de este siglo la ciudad de Concepción sentía la necesidad de tener una Universidad, pero este anhelo sólo vino a tomar forma en 1917, cuando se formó el Comité pro Hospital Clínico y Universidad de Concepción.

El comité tenía como presidente a don Enrique Molina, vicepresidente al prestigioso médico penquista Dr. Virginio Gómez, secretario general al profesor Carlos Soto Ayala y tesorero a don Eliseo Salas. El trabajo fundamental de este comité fue formar el ambiente propicio para iniciar una de las dos grandes obras.

Fue en los primeros días del año 1919 cuando este comité, presidido por el Dr. Virginio Gómez, por estar ausente en Estados Unidos su presidente, en un rasgo de audacia, acordó crear una Escuela Dental, una de Farmacia, un curso de Pedagogía en Inglés y una Escuela de Química Industrial.

Las actividades universitarias se iniciaron en la modesta casita de la calle Caupolicán 262, donde había una oficina, una sala de clases y los laboratorios se proyectaba instalarlos en la cocina.

El mejor laboratorio de la naciente Universidad era el de Química. Su primer material estaba formado por el que podía traer en mis bolsillos de la Escuela de Ingenieros de la Armada; Física no tenía nada, las clases se hacían en el Liceo de Hombres y la Éscuela Dental disponía de un viejo sillón de peluquería.

El profesorado que inició las labores universitarias estaba formado por profesores de los establecimientos educacionales de la región y profesionales prestigiosos de la zona.

La primera clase universitaria la hice yo a mediados de marzo. Para solemnizarla asistió parte del directorio con su presidente y casi llenaron la pequeña sala de clase, quedando gran parte de los alumnos fuera de ella. 
Como no habia ayudantes, hizo de tal, en esta primera clase, don Edmundo Larenas, distinguido Notario de Concepción y hombre muy dedicado a la mineralogía. No había gas en la casa y una lamparilla de alcohol nos sacó de apuros.

La gran afluencia de alumnos casi nos llevó a un fracaso. La sala de clase y la casa eran muy pequeñas, había que pensar en otra. Don Augusto Rivera Parga, motor y a'ma en todos estos afanes y a quien tanto debe la Universidad, resolvió el problema. Encontró una vieja casa en O'Higgins 850, abandonada por el Club Francés. Recuerdo que al entrar a una de sus piezas el piso se hundió.

Don Augusto Rivera transformó esa vieja casa en una Universidad, cada Escuela tenía su sala de clase y su laboratorio.

Los recursos universitarios, formados por cuotas de los socios y personas de buena voluntad, algo de derechos de matrícula y donaciones o subvenciones municipales, en que la de Perquenco fue la que mejor se cristalizó, sólo alcanzaban para pagar a los profesores, a razón de $\$ 50$ por cátedra, suma que destinábamos a pagar ayudantes.

Pero para la naciente Universidad quedaba el problema más grave y trascendental: si el Consejo Universitario de Santiago la reconocía y le enviaba comisiones examinadoras. Una comisión formada por el Dr. Gregorio Amunátegui, Decano de la Facultad de Medicina; Dr. José Ducci, secretario de la misma Facultad y el Dr. Germán Valenzuela Basterrica, Director de la Escuela Dental de Santiago, debía informar sobre la eficiencia de la naciente y pobre Universidad. ¿Qué podríamos mostrar? Lo que habían aprendido nuestros alumnos, las prácticas de laboratorio, etc. Hicimos clases, mostramos formularios de prácticas de laboratorio, poco difundidas en esos tiempos, etc., etc. Para nuestra tranquilidad y responsabilidad el informe de la comisión fue muy favorable y en diciembre llegaron las comisiones examinadoras presididas por los profesores titulares de las Escuelas de Santiago y abundaron las 2 y 3 coloradas, en todos los exámenes.

El segundo año universitario casi fue más terrible que el primero. Hubo necesidad de contratar algunos profesores en Santiago y 
otras ciudades y lo más grave de todo, no había con qué pagarlos. Los conciertos, jiras a los pueblos sureños, etc., no daban resultados eficientes. Entonces comenzó a nacer la idea de hacer donaciones con sorteos, corriendo el peligro de caer en manos de la justicia.

Por suerte nada pasó y la Universidad siguió su marcha más tranquila y con mayor entusiasmo.

Llegó el año 1923 y la Universidad de Chile nos pidió crear una Escuela de Medicina. Aunque eran proyectos mayores y de gran responsabilidad, el honorable directorio acordó crear los primeros años y me nombró su director organizador. En sus instalaciones y construcciones se gastó con mayor largueza y para su inauguración vino de Santiago una comisión presidida por el señor Rector de la Universidad de Chile, don Gregorio Amunátegui, y hubo actos académi$\cos$ y banquetes.

No voy a cansarlos siguiendo cronológicamente la marcha de la Universidad; ella fue ascendiendo vertiginosamente bajo la mano firme y la mente serena y fecunda de don Enrique Molina y gracias a las donaciones con sorteos ideadas por don Luis David Cruz Ocampo.

Pero debo hacer resaltar que ya en esa época propiciamos el desarrollo de la extensión universitaria. Se trajeron distinguidos conferenciantes, se organizaron exposiciones, congresos, etc. En 1927, se celebró el Primer Congreso Nacional de Farmacia, con delegados de Arica a Magallanes, y sus conclusiones hicieron modificar los planes de estudios y métodos de enseñanza de la Escuela de Santiago. Nació la Federación de Estudiantes y la Facultad de Ciencias, la primera de la Universidad y que hoy anhelamos nuevamente.

Aunque esta joven y paupérrima Universidad no tenía hermosos edificios y grandes laboratorios, contaba, en cambio, con un profesorado todo corazón, en que la Universidad era carne de su carne y gracias a esto y al tino de sus dirigentes, creció rápidamente, con alma y espíritu sanos.

Esta Universidad, "este monumento labrado en la roca con las uñas", como dijo un literato argentino que nos visitó en esos prime- 
ros años, ha logrado que en su patria se reconociera rápidamente su valor, en tal forma que hoy en muchos aspectos es similar a la centenaria Universidad de Chile: puede otorgar títulos de licenciados en Leyes, Medicina, casi lo mismo en Dentística y Pedagogía; y ya sus ingenieros entrarán directamente al Colegio de Ingenieros de Chile y su curso normal otorga el título de normalista.

Pero no sólo en Chile ha ganedo prestigio; universidades extranjeras reconocen su valer y sus títulos. La Universidad de París y todas las francesas reconocen la equivalencia del título de Ingeniero y en algunas muy prestigiosas de Estados Unidos, como la de Northwestern (Chicago, Illinois) pueden nuestros egresados llegar directamente a optar al doctorado, sin pasar por el Master; algo semejante en la de París.

$Y$ así ha seguido nuestra Universidad su marcha ascendente, marcha triunfal, que pudo haber sido cantada por Rubén Darío y que ha dejado en el camino Ciencia, Arte, Espíritu de Trabajo y de Sacrificio.

Llegamos al año 1956 - año 37 de la Era Universitaria- y nuestro rector don Enrique Molina, alma y vida de nuestra Universidad, por una grave dolencia no puede seguir ante su Universidad. Entonces el Claustro Pleno, por una gran mayoría, elige un nuevo rector: don David Stitchkin B. Hombre joven, dinámico, de gran cultura y preparación; gran universitario y gran inteligencia que desea seguir la marcha triunfal de la Universidad. Pero lo mismo que nosotros hace más de 30 años tropieza con las dificultades económicas, no hay fondos para nuevas creaciones, $y$, también, en un rasgo de audacia se lanza en compañía de nosotros, los viejos fundadores, a crear nuevas carreras universitarias, a abrir nuevos horizontes y nuevos campos de acción que lleven la Universidad a los campos, a las minas, al país entero con su difusión cultural, por medio de la radiodifusión y la imprenta. ¡Qué la fortuna lo acompañe para bien del país!

Y termino, señoras y señores, recordando que el afio 1919 un grupo de dirigentes universitarios, profesores y alumnos visionarios 
encendieron la antorcha universitaria y siendo yo uno de ellos os pido, a vosotros ex alumnos, que formáis gran parte del honorable sonsejo y honorable directorio y que ya la tenéis en vuestras manos, y a vosotros jóvenes alumnos que la tomaréis más adelante, no olvidéis nuestro lema Por el desarrollo libre del espiritu, sin sectarismo, sin banderas políticas, sólo mirando en lo alto nuestra estrella solitaria, trabajéis porque siga la marcha triunfal de nuestra Universidad".

\section{PREMIOS "UNIVERSIDAD"}

La siguiente es la nómina de los egresados a los que se les hizo entrega de los premios "Universidad de Concepción":

Escuela de Leyes: señorita Irma Bavestrello Bontá; Escuela de Periodismo, señorita Italia Gnecco Gnecco; Escuela de Medicina, señor Jaime Taboada Liewaldt; Escuela de Química y Farmacia, señor Ricardo Woerner Vogel von Falckestein; Escuela de Enfermeras, señorita Eugenia Jeria De Folliot; Escuela de Odontología, señor Gabriel Delgado Riese; Escuela de Ingeniería Química, señor Avelino Garca Uteau; Escuela de Educación, Curso Castellano, señorita Rosalía Bustos Quinteros; de Francés, señorita Amandina Vera Peña; de Biología y Química, las señoritas Sonia Oyarce López y Ana Sánchez Chávez, y de Matemáticas y Física, el señor Walter Stuven Contzen.

\section{PREMIO “ATENEA"}

El premio “Atenea” que la Universidad de Concepción concede anualmente a una obra literaria, ha sido otorgado por el año correspondiente a 1956 a don José Miguel Vergara Prieto por su novela Daniel o Los leones dorados, publicada por la Editorial Pacífico.

$\mathrm{El}$ autor de esta obra es un joven escritor que ha residido largamente en el extranjero y cuya aparición en el mundo de las letras le da de inmediato el espaldarazo que lo acredita novelista de relevantes calidades. Dentro de la tradición de la novela chilena, Daniel 
- Los leones dorados queda al margen de toda clasificación en escuela o tendencia, pues la trama de la obra se singulariza por estar ambientada en Inglaterra y España y ser sus protagonistas personajes agitados por inquietudes trascendentes relacionadas con la fe religiosa. José Miguel Vergara ha sabido crear la atmósfera novelesca con gran vigor y propiedad y perfilar el carácter de los seres con tal relieve que ellos se corporizan en la imaginación del lector con realidad viviente. Con esta novela la literatura chilena se evade de los límites de lo regional o nacional para transponer las fronteras de lo universal, ya que los problemas que se presentan en Daniel o los leones dorados son de aquellos impulsados por pasiones que afectan a cualquier individuo, sin categorías específicas de nacionalidades o razas. Si bien en la forma se advierten vacilaciones e incorrecciones expresivas, el interés humano de su contenido le afianzó un extraordinario buen éxito de crítica y de librería.

El jurado que confirió el referido premio estaba constituido por el rector de la Universidad de Concepción, don David Stitchkin Branover, don Avelino León Hurtado, secretario general de la Universidad, don Carlos Martínez, director de la Escuela de Educación, y don Milton Rossel, director de "Atenea".

\section{COMUNICACIONES DE LA UNIVERSIDAD DE CHILE A DON ENRIQUE MOLINA}

Damos a continuación la nota enviada a don Enrique Molina por el señor Rector de la Universidad de Chile, don Juan Gómez Millas, en la cual se le comunica habérsele conferido el título de Doctor Honoris Causa, distinción la más alta que otorga nuestro principal centro de estudios superiores. Asimismo, se reproduce el texto de la leyenda del diploma en que se acredita tal distinción. También insertamos la nota del señor Decano subrogante de la Facultad de Ciencias Jurídicas y Sociales de la Universidad de Chile, don Leopoldo Ortega Noriega, en que se le da cuenta de su designación como Miembro Honorario de dicha Facultad. 


\section{UNIVERSIDAD DE CHILE}

Santiago, 25 de mayo de 1957

Al señor don Enrique Molina Garmendia

Concepción

"Distinguido señor:

"Cábeme el alto honor de comunicar a Ud. que el Consejo Universitario en su sesión de 23 de mayo, acordó, por la unanimidad de sus miembros, otorgar a Ud. el título de Doctor Honoris Causa de la Universidad de Chile.

“Al participar a Ud. esta decisión, cúmpleme también transmitirle los elogiosos términos que alrededor de su persona se vertieron en esta sesión por su dilatada labor en el desarrollo de la enseñanza y la sobresaliente y fecunda continuidad de una de las carreras más destacadas en la educación que ha tenido el país a lo largo de toda su historia. Rica ella en realizaciones de vastísimos alcances, recibió la inspiración precursora de las mejores influencias para lograr la transformación de la enseñanza chilena hacia objetivos que llevan a la formación humanística y técnica que hacen de ella un modelo de superación, poniéndola al nivel de las necesidades de nuestro tiempo y conformar la personalidad a las urgencias sociales y las más trascendentales del espíritu.

"Su formación intelectual, su cultura pedagógica y filosófica que Ud. supo formar y captar en sus lecturas, sus estudios y sus viajes tan provechosos, conformaron en Ud. una mente abierta a todas las inquietudes de reforma educacional, principalmente en sus ramas secundaria y superior, lo que, unido a su natural benevolencia, distinción y talento, lograron hacer de Ud. una de las personalidades más descollantes y veneradas como maestro de nuestro país, en la hora presente. Su nombre así llegó a ser en el corazón y en los labios de 
muchas generaciones de chilenos, arquetipo de bondad, afecto y de cordialidad humana.

"La Universidad de Chile, hija predilecta de la República desde los albores de nuestra vida independiente, miró siempre con cordial simpatía el nacimiento, en el presente siglo, de la joven y progresista Universidad de Concepción. La consideró su hermana y vio con legítimo orgullo su crecimiento y desarrollo. Nunca, a lo largo de su historia, una nube de desinteligencia cubrió el cielo cristalino de las cordiales relaciones que se han mantenido entre nuestros dos Institutos. Vinculada a las necesidades más apremiantes y directas de una de las regiones más ricas del país, la Universidad de Concepción, fruto de sus desvelos y de su tesonera labor, ha conseguido un prestigio nacional cuyas ondas rebalsan el límite de nuestras fronteras y, para esta Casa, la persona de su Rector y las luces de su espíritu, se hermanan e identifican al prestigio de la que, durante los 37 años de su vida, prosperó bajo su dirección, consiguiendo que cada vez, y a medida que ella iba adquiriendo la mayor edad, este vínculo se hiciera más efectivo y fecundante.

"Al comunicar a Ud. el acuerdo de conferirle el título de Doctor Honoris Causa, galardón que la Universidad de Chile ha dispensado sólo en una ocasión anterior a nuestra gran poetisa, Gabriela Mistral, quiere unir más estrechamente su nombre a los recuerdos más venerados de este Instituto y estrechar, al mismo tiempo, los nexos que la enlazan a la Universidad de Concepción, honrando el nombre de su padre espiritual y fundador.

"Quiera Ud., en esta oportunidad, recibir la reiteración de los sentimientos más cordiales de admiración y respeto del Consejo Universitario, que el Rector y el Secretario General que suscriben, quieren transmitirle al abandonar su larga y brillante carrera en la educación.-Juan Gómez Millas, Rector.-Guillermo Feliú Cruz, Secretario General". 


\section{LEYENDA DEL DIPLOMA}

Por cuanto don Enrique Molina Garmendia se ha distinguido como uno de los más eminentes maestros de la República y una de las más altas figuras de la Filosofía en América, la Universidad de Chile viene en designarlo Doctor Honoris Causa en reconocimiento de sus elevados méritos y del permanente valor de su obra como educador, hombre de letras y Rector de la Universidad de Concepción. Firmado y refrendado en Santiago de Chile a 23 de mayo de 1957.

Juan Gómez Millas, Rector de la Universidad.
Guillermo Feliú Cruz, Secretario General.

\section{DISTINCION A DON ENRIQUE MOLINA}

A pesar de que su vida discurre en apacible retiro, siguen sumándose a don Enrique Molina las distinciones que se tiene ganadas por su fecunda y extensa labor intelectual, docente y directiva. Así, últimamente se le ha conferido el título de Miembro Honorario de la Facultad de Ciencias Jurídicas y Sociales de la Universidad de Chile.

Para la Universidad de Concepción y en particular para "Atenea" son profundamente gratos estos reconocimientos a quien fuera fundador, presidente y rector de este organismo de estudios superiores y animador y orientador de la revista en que volcara sus inquietudes trascendentes en torno a los problemas del ser y del cosmos.

\section{UNIVERSIDAD DE CHILE}

Santiago, abril 12 de 1957

Al ex Rector de la Universidad de Concepción

Presente

"Ilustre maestro:

"Nos es profundamente satisfactorio comunicarle que la H. Facultad de Ciencias Jurídicas y Sociales de la Universidad de Chile, 
en sesión celebrada al día 28 de marzo último, rindió a Ud. un homenaje con motivo de su retiro de la Rectoría de la Universidad de Concepción después de más de sesenta años de permanente dedicación a la enseñanza y en el curso del cual se destacaron sus excepcionales méritos como educador, pensador, jurista y, especialmente, como creador y organizador del plantel universitario que lleva como lema "Por el desarrollo libre del espíritu".

"La Facultad en atención a estos insignes títulos, acordó por la unanimidad de sus miembros presentes, otorgar a Ud. la calidad de Miembro Honorario de la Corporación, el honor más alto que puede conferirle.

"Al comunicarle este acuerdo, no ocultamos la profunda satisfacción personal de ser los encargados de dar a Ud. conocimiento de tal designación que, junto con distinguir al hombre eminente, honra también a la Corporación.

"Saludan atentamente a Ud., affmos. y Ss. Ss.-Leopoldo Ortega Noriega, Decano suplente.-Luis Cousiño Mac-Iver, Secretario Facultad".

\section{BALDOMERO SANIN CANO}

No cabe una breve nota necrológica sobre el erudito y proficuo crítico colombiano. Su larga existencia - ha muerto próximo a los cien años- estuvo permanentemente encauzada a exaltar los valores del espíritu que de alguna manera han agitado la conciencia del hombre contemporáneo. Crítico por sobre todo, Sanín Cano estuvo atento a cuanto libro interesante se ha producido en el mundo occidental, y era el primero, en lengua castellana, en comentarlo y difundirlo. Su apetencia de cultura y su preocupación de estar al día en materias literarias, filosóficas, filológicas, sociales, políticas, etc., lo sitúan en lugar eminente junto a Alfonso Reyes y en la misma línea de esos sembradores de ideas que fueron Montalvo, Hostos, Martí, González Prada. Si bien es cierto que su producción tuvo un carácter 
periodístico, ya que su labor más activa en las letras fue la de colaborador de los grandes diarios de su patria y América, muchos de sus estudios han sido compilados en libros, ampliándose así la vigencia del artículo que pareció destinado a olvidarse junto con la hoja efímera del periódico. Por la densidad de sus ideas, por la amplitud de sus puntos de vista, por la objetividad de sus enfoques, bien puede decirse de Baldomero Sanín Cano que fue un hombre universal.

"Atenea", al adherir al duelo que afecta a las letras colombianas, anuncia para un número próximo el homenaje digno de las relevantes cualidades intelectuales y morales del maestro.

DISCURSO PRONUNCIADO POR DON LUIS BURGOS FUENTES EN CONMEMORACION DEL SEGUNDO ANIVERSARIO DE LA FUNDACION DEL INSTITUTO PEDAGOGICO DE LA UNIVERSIDAD DE CHILE, EN VALPARAISO

Señoras y señores, henos aquí empeñados en un acto de recordación de una de esas cosas que merecen pervivir en la memoria de los hombres: me estoy refiriendo al acto de alta trascendencia cumplido dos años ha en esta ciudad bellísima por la Universidad de Chile, al asumir la tuición y hacer suya una Escuela Pedagógica nacida de los impulsos generosos del profesor don Oscar Guzmán y sostenida heroicamente por él en sus primeros pasos.

$Y$ al mismo tiempo, y sin contradicción, nos empeñamos en honrar la memoria de uno de los espíritus más excelsos que ha producido nuestra tierra en la esfera del arte y en nuestra profesión pedagógica: hablo de Gabriela Mistral, lírica y maestra sin par.

El saber filosófico fue el saber universal, el que abarcaba cuantas esferas de la realidad habían explorado los hombres con rigor científico.

De esa matriz se fueron desprendiendo, en el transcurso del tiempo, los especializados saberes cuya labranza requerían las urgen- 
cias vitales con concentrado afán y olvido del resto del mundo: como la rama instrumental de las Matemáticas, cultivada especialmente desde milenios; como la rama del Derecho, que, por referirse a las relaciones de los hombres entre sí y respecto de las cosas, había menester desde antiguo de consideraciones exclusivas; como la rama de las Ciencias Físicas que, al alborear el Renacimiento, sedujo al hombre del tiempo nuevo, transido de ideales de humanidad puramente terrestre; como la rama de las Ciencias del Espíritu que en nuestros días mismos pugnan por establecerse como entidades independientes de su matriz filosófica.

$\mathrm{Y}$ digo esto porque se advierte la trascendencia especialísima de crear una Escuela de Filosofía y Letras en esta ciudad señera de la vida chilena, en que se conjugan las bellezas del Cosmos con las excelencias de los afanes del hombre en todas las latitudes del quehacer humano: ciencias, letras, artes, industrias, comercio, etc.

Cuando tal se hizo, se dio patente a la ciudad de Valparaíso de mayoridad espiritual. No digo, por cierto, que el solo hecho de la fundación le dé primacía entre sus pares, las ciudades universitarias del mundo, pero sí que esta calidad la obliga a labrarse un nombre en la vida del espíritu.

Por eso, al recordar el hecho de su fundación, tan reciente, estamos penetrados de la importancia del evento y de la obligación que comporta para las actuales y futuras generaciones de educadores y educandos que por sus aulas pasen.

Ahora bien, esta Facultad de Filosofía, en su advocación complementaria de Facultad de Letras o de Ciencias de la Educación, reclama como cosa suya la figura singular de Gabriela Mistral, artista y maestra que, no ha mucho, cerró el círculo de su humana existencia para penetrar en la vida perdurable de la Fama como creadora de belleza y en la vida eterna, como criatura de Dios.

El poeta es un creador en el reino del espíritu y su creación consiste en el descubrimiento, en la revelación de hondones de humanidad soterrada y oculta. 
El poeta descubre el mundo y la vida desde un ángulo de visión personalísimo que es, sin embargo, un ángulo de visión propio de su estirpe, de la grey humana a que pertenece, de manera que al revelarse, la revela y le entrega en posesión plena lo que oscuramente y sin saberlo le pertenecía.

Gabriela Mistral ha sido ese adalid, gran capitán y conquistador de nuestro reino espiritual. Y por ella disfrutamos ahora de modalidades plenamente vigentes de nuestra chilenidad que subyacían en nuestra alma nacional.

Por ello, la Facultad de Filosofía y Letras y Cienciàs de la Educación ha de parar mientes en su peripecia vital y artística y rendirle acabada pleitesía.

Hay en la vida de Gabriela Mistral tres momentos capitales:

El de la alborada campesina;

El del maestrazgo nacional e internacional;

El del señorío del mundo.

Nacida en las postrimerías del siglo, en 1889 -cuando Rubén Darío se asomaba a nuestras tierras y en ellas a la gloria-, hállase Lucila Godoy Alcayaga incluida en un mundo rural que luminosas montañas circunscriben y cuya soleada tierra rinde óptimos frutos, mundo sin embargo aledaño y excéntrico respecto de la urbe que entonces más que ahora era la capital y casi exclusiva sede de la vida espiritual chilena.

Y hállase, además, hija y ahijada de mujeres solas, porque el, progenitor de sus días - que había soñado pastorear almas en el nombre de Dios y consoládose apacentándolas en el campo de la cultura elemental en el noble y oscuro oficio de maestro de primeras letras- dase por fin a trashumar cuando su hija Lucila contaba sólo dos años de edad, para nunca más volver, dejándola a merced de su madre, que le enseñaría la virtud del amor hecho dulcedumbre, y de su media hermana Emelina, que le mostraría la virtud del amor que combate sin desmayo y habíale de volvérsele el vivo modelo de "la mujer fuerte" de que habla la Biblia. 
Por lo cual, la niña inducida en el hogar por las vías del saber elemental y perfeccionada en él en alguna escuela de vecindad, se hace a su vez monacilla del oficio docente, desempeñándose como Ayudanta de escuelitas de su tierra cuando sólo contaba dieciséis años de edad.

$\mathrm{Y}$ en ese preciso punto de su vida, comienza un triple ejercicio de vocación erótica: el del amor a varón que integrara su vida individual; el del amor a las criaturas que se daba a apacentar espiritualmente; el del amor a la gloria literaria, que la condujera a apacentar humanidades.

Su amor carnal incendia su alma que efervesce de anhelos.

Pero en esa hora de su aurora "se le llena de sombras el camino".

Las autoridades docentes de la Escuela Normal de La Serena la estigmatizan: no ha de entrar en esas aulas la novel escritora, cuyos artículos de periódico denuncian un espíritu de rebeldía que sería sin duda pernicioso para la formación de futuras maestras.

Mientras el amado, desasido de su veste, vaga por ajenos senderos de amor, sumiéndola en "desolación" y, hora aciaga, por oscuras razones, se va de este mundo, "trizándose las sienes como vasos sutiles".

Así terminaba la etapa eglógica de su niñez en un furioso vendaval de adolescencia.

La Maestra Rural, transida de dolor, y anonadada, accede a la capital en el año de las fiestas centenarias de su patria. Y obtiene, tras un "Examen de Competencia", un título saneado y bastante para ejercer la docencia primaria en las escuelas públicas de Chile.

Y ella, no sabemos cómo, se ingiere en la enseñanza secundaria: en la fronteriza Traiguén, llamada de los trigos; en la capital del desierto salitrero, Antofagasta; en Los Andes, cabe el Cristo Redentor. Todo ello en breve tiempo.

Y va acendrando poéticamente las brasas de su pasión erótica.

Desde su alto retiro concurre, en 1914, a la llamada de la Sociedad de Escritores y Artistas. Y sus Sonetos de la Muerte se lleva- 
rán la "Flor Natural" de esos Juegos Florales y la pondrán en los umbrales de la Fama con el nombre de Gabriela Mistral.

Entonces su vida pública toma un ritmo de celeridad creciente. Escritores y artistas de Chile y del extranjero solicitan su amistad.

Don Pedro Aguirre Cerda, Ministro de Justicia e Instrucción Pública, la transmuta en Directora de Liceo: en Punta Arenas, en Temuco, en la propia capital del país.

Es la hora de remontar el vuelo allende las fronteras.

Por mediación de Federico de Onís, eminente crítico literario y catedrático en la Columbia University, su obra primigenia Desolación es editado por el Instituto de las Españas en Nueva York.

Es la primera y la más trascendental de sus embajadas.

Vasconcelos, Ministro de Educación de México, la invita a colaborar con él en la reforma educacional de su país que entonces emprende.

Entretanto, la Universidad de Chile, le concede "por gracia" el título profesional de "Profesora del Estado en la signatura de Castellano".

Concluida su excepcional misión, viaja por los Estados Unidos y por España y torna a la tierra patria, triunfalmente, por la vía del Atlántico.

“¿Qué político o qué grande de la tierra viaja en nuestra nave, capitán -pregunta la poetisa-, que recibe este homenaje?"

"Son las escolares de Montevideo que rinden a Ud. tributo de admiración" - le responden.

"Y entonces - confiesa- lloré por el inmerecido honor que alcanzaba: fue el día más feliz de mi vida".

De modo tal se cumple el ciclo mágico de la carrera docente de la Maestra Rural de Montegrande en el término de cuatro lustros.

Falta sólo la apoteosis mundial.

Ya no se trata de eminencias de las letras o de la política que la solicitan y tienen por suya, es el concierto de las naciones del mundo, es la Liga de las Naciones, la que ocurre a sus merecimientos y le pide colaboración. 
$\mathrm{Y}$ es el gobierno de Chile el que - superando un instante oscuro- crea en su homenaje una modalidad institucional en su servicio de Relaciones Exteriores: Gabriela Mistral será Cónsul de Chile en alguna tierra extranjera. Otros gobiernos convertirán esta gracia y justicia en la de Cónsul Vitalicio. Y así honrándola se honrarán esos gobernantes y honrarán la clara estirpe de nuestra política y de nuestra cultura.

Entretanto, primero el Premio Nobel de Literatura y, años más tarde, el Premio Nacional pondrán el remate soberbio a su carrera literaria: la voz humilde y religiosa que escucharan los estudiantes de español pastoreados por Federico de Onís sonará por los ámbitos de la tierra toda en gloria y majestad, en suma excelsitud. Y la creadora de alma habrá ido desde la extrema Desolación a la apoteosis.

El gobierno de Chile, una vez más, en feliz inspiración la llama a la tierra como huésped oficial en 1954 para que su pueblo la vea y la aplauda y la admire renovándole su devoción amorosa.

Entonces todo está consumado. No se puede ir más lejos. Y llega la hora de morir. Ello ocurre en Nueva York, lejos y cerca de su tierra, en el corazón del mundo de nuestros días, en enero de 1957.

Las naciones del mundo, condolidas, expresan su sentimiento al gobierno de nuestro país. De tal modo la Maestra Rural nos representa esencialmente y es parte del patrimonio de cultura universal.

Tales son los hechos, estudiantes, atañederos a este evento espiritual que se llamó Gabriela Mistral.

¿Qué significan tales hechos para nosotros los del oficio docente?

Significan que en esta nación nuestra - que es, sin duda, una pequeña gran nación- no hay nacimiento por excéntrico que sea geográficamente respecto de los grandes centros de las cultura nacional ni progenie sin ventura material que obste al ascenso de un grande espíritu en que a un corazón generoso, ardientísimo, se una una voluntad poderosa, inquebrantable y una inteligencia lúcida de humanidad profunda. Esa viva conciencia colectiva, que descubra, rescata y aúpa los valores auténticos es la garantía de nuestro mejor 
derecho, de nuestra esperanza fundada; la auténtica igualdad de oportunidades.

Significa también que la raíz profunda de nuestro oficio es el vivo amor a la criatura humana, un amor sin el cual la jerarquía suma del apostolado en que nuestra función consiste, degeneraría en servidumbre y venalidad sin grandeza y sin posible dicha.

Significa, por último, que este oficio oscuro lleva implícita una posibilidad de lumbre universal capaz de convertirnos eventualmente en rectores de greyes humanas y de la humanidad toda, si de consuno obran el gratuito don divino y la heroica virtud humana, de que emergen poetas, héroes y santos.

\section{ELECCIONES Y CAMBIOS EN LA SOCIEDAD DE ESCRITORES}

En el curso del mes de abril último, la Sociedad de Escritores de Chile eligió el siguiente directorio: presidente, Ricardo A. Latcham; vicepresidente, Rubén Azócar; secretaria, Matilde Ladrón de Guevara; tesorero, René Hurtado Borne; directores, Ester Matte, Luis Merino Reyes, Pablo Neruda, Armando Cassigoli, Jorge Onfray, Baltasar Castro y Manuel Vega.

Posteriormente, fueron aceptadas las renuncias de Luis Merino Reyes y Ester Matte, siendo reemplazados por Benedicto Chuaqui y Emilio Oviedo. Además fue elegido Miguel Vicuña, en reemplazo de Matilde Ladrón de Guevara, quien renunció por viaje al extranjero.

\section{NUEVO ACADEMICO}

Por unanimidad fue elegido Académico de la Lengua don Jaime Eyzaguirre Gutiérrez, historiador de justa nombradía y director de publicaciones culturales, como "Finis Terrae" y la revista "Estudios". 


\section{DIRECTIVA DEL SINDICATO DE ESCRITORES}

La directiva del Sindicato de Escritores quedó compuesta en la siguiente forma: presidente, Juvencio Valle; tesorera, Mila Oyarzún; secretario, Luis Serey Pizarro; directores, Mario Ferrero y Fernando Lamberg.

\section{PREMIO DE LA CAMARA DEL LIBRO}

El jurado compuesto por Alberto Romero, en representación de la Sociedad de Escritores de Chile, Manuel Vega, por el PEN Club, y Luis Merino Reyes, por el Sindicato de Escritores, concedió, por unanimidad, el premio "Mauricio Fabry", de la Cámara del Libro, ascendente a la suma de $\$ 150,000$, a Mauricio Sescovich Abramson, por su obra intitulada Humilde Rebeldía. Asimismo, otorgó Mención Honrosa a la novela Dos cabritos en Chiloé, de don Tancredo Pinochet. La Cámara Chilena del Libro tiene el propósito de repetir anualmente sus premios, en los distintos géneros literarios.

\section{CONCURSO DE CUENTOS "MARIANO LATORRE"}

En el Concurso de Cuentos organizado por los amigos del novelista Mariano Latorre, con premios donados por el señor Salvador Hirmas, resultaron agraciados con el primer premio Carmen de Alonso y Lautaro García; Benjamín Morgado obtuvo el tercer premio, pues el segundo se declaró desierto y se otorgaron también cuatro menciones honrosas. El jurado estuvo compuesto por Ricardo A. Latcham, Manuel Vega, Roberto Meza Fuentes y Héctor Fuenzalida.

\section{PREMIO DE LA SOCIEDAD DE ESCRITORES DE CHILE}

El premio anual establecido por la Sociedad de Escritores de Chile, correspondió para el año 1956 al libro de cuentos Tierra del 
Fuego, de Francisco Coloane, publicado por la Editorial del Pacífco. El premio ascendente a la suma de $\$ 100,000$ fue donado por doña Clara Rosa Otero, filántropa venezolana, antes benefactora de la Escuela de Periodismo. El jurado estuvo compuesto por los presidentes de instituciones literarias, autores que han obtenido el Premio Nacional de Literatura y críticos literarios.

\section{CONCURSO DE CUENTOS PERU}

En el Concurso de Cuentos Perú, organizado por la Asociación del Libro Americano, resultó vencedor Guillermo Blanco, antes laureado en el mismo género por el Sindicato de Escritores, "El Nacional" de México y "El Mercurio" de Santiago de Chile.

\section{MONUMENTO A DON ENRIQUE MOLINA}

Fue declarado desierto el concurso del monumento a don Enrique Molina, rector honorario de la Universidad de Concepción; se presentaron a este concurso doce escultores chilenos que optaron a tres premios de 250 mil pesos. El jurado estuvo compuesto por autoridades de la Universidad de Concepción, miembros de la Facultad de Bellas Artes, arquitectos y un escultor, en representación de los concursantes.

\section{ACTIVIDADES UNIVERSITARIAS}

\section{Abril de 1957}

1. - Se recibe la visita del rector de la Universidad de Chile, don Juan Gómez Millas, quien es atendido por las autoridades universitarias penquistas. La visita del señor Gómez Millas obedece a una invitación de nuestra Universidad, se toman diversos acuerdos que favorecen a ambos establecimientos. 
8.-El Club Aéreo Universitario de Concepción, bendice una nueva máquina. Es madrina la señora Fanny Litvak de Stitchkin.

9.-En el Salón de Honor se efectúa la conferencia de don Orlando Baettig sobre "Impresiones de un viaje a Israel".

12.-Se dan a conocer planes de ayuda mutua entre Universidades Técnicas y de Concepción.

12.-Un predio de la Escuela Agrícola de Chillán queda a nombre de la Universidad de Concepción.

23.-Don David Stitchkin es designado vocal del Comité de Defensa Jurídica de la Democracia.

23.-Don Jorge Acuña Estay es designado subdirector de las Escuelas de Leyes, Periodismo y Economía y Comercio.

25.-Don Enrique Molina es nombrado Miembro Honorario de la Facultad de Leyes de la Universidad de Chile.

26.-El gobierno italiano ofrece una beca para egresados de nuestra Universidad.

29. -El señor David Gottieb, experto de la FAO en Alimentación y Agricultura, visita nuestra Escuela de Agronomía, continuando a Chillán.

30.-En el Salón de Honor se efectúa la asamblea general de socios de la Universidad.

Mayo de 1957

11. - La cantante folklórica señorita Violeta Parra, de fama internacional, ofrece un recital en el Salón de Honor.

14.-El personal administrativo y docente de la Universidad conmemoró el aniversario del establecimiento con un cóctel en el Restaurante "Don Quijote".

14. - Con un acto académico se celebra el Día de la Universidad en el Teatro Concepción, entregándose los diversos premios a los mejores alumnos de las distintas escuelas. Habla el director de la Escuela de Ingeniería Química, don Salvador Gálvez. A nombre de los premiados habla la egresada de la Facultad de Ciencias Jurídicas y 
Sociales, señorita Irma Bavestrello Bontá. Por su parte, el rector, señor David Stitchkin, hace entrega en el mismo acto del diploma que acredita la calidad de Miembro Honorario de la Universidad de Concepción, al profesor fundador, señor Humberto Vergara.

Además, el rector señor Stitchkin, por una cadena radial, dirige un mensaje a la ciudadanía de la zona sur del país.

16.-Se celebran los Juegos Florales organizados por la Federación de Estudiantes de esta Universidad.

17.-En Talca se inician las conferencias por profesores de la Universidad. Habla sobre "Folklore" el señor Caupolicán Montaldo.

24.-Se inaugura la "Exposición de Atomos para la Paz".

27.-El profesor don Roberto Munizaga diserta en el Salón de Honor, sobre "La educación en los Estados Unidos de Norteamérica". Es atentamente escuchado y largamente aplaudido.

29.-Se otorga el premio "Atenea" 1956, al libro "Daniel y los Leones Dorados”, de José Manuel Vergara. 